\title{
Antibody (IgG, IgA, and IgM) to baker's yeast (Saccharomyces cerevisiae), yeast mannan, gliadin, ovalbumin and betalactoglobulin in monozygotic twins with inflammatory bowel disease
}

\author{
E Lindberg, K-E Magnusson, C Tysk, G Järnerot
}

\begin{abstract}
To assess whether dietary antigens play a role in inflammatory bowel disease, 26 monozygotic twin pairs with inflammatory bowel disease and $\mathbf{5 2}$ healthy controls were investigated for serum antibodies (IgA, IgG, IgM) against ovalbumin, betalactoglobulin, gliadin, whole yeast (Saccharomyces cerevisiae) and yeast cell wall mannan. The twins were made up of five pairs concordant and nine pairs discordant for Crohn's disease, and two pairs concordant and 10 pairs discordant for ulcerative colitis. Two patients with Crohn's disease had a slight increase in disease activity, the others were in clinical remission. Two striking observations were made: first, individuals with ulcerative colitis were indistinguishable from healthy twins, and controls except for the response to gliadin. Both healthy and diseased twins had higher IgA levels to gliadin than controls. Second, twins who had developed Crohn's disease displayed higher antibody titres towards yeast cell wall mannan in particular, but also to whole yeast (Saccharomyces cerevisiae) of all antibody types (IgA, IgG, and IgM). In contrast, the response to gliadin, ovalbumin, and betalactoglobulin did not differ from healthy twins and was even lower than in the controls. The results argue against an increased systemic antigen presentation caused by an impaired mucosal barrier in the inflammatory bowel disease. Rather, they suggest that yeast cell wall material - that is, mannan, or some antigen rich in mannose and cross reacting with mannan, may play an aetiological role in Crohn's disease, but not in ulcerative colitis. The increases in IgA and IgM, as well as IgG suggest that local and systemic immune systems are selectively activated by antigen(s) present in the cell wall of baker's yeast.
\end{abstract}

Food antigens have been implicated in the aetiology of inflammatory bowel disease. ${ }^{1-13}$ In particular cow's milk proteins have been thoroughly investigated. ${ }^{1-10}$ The results differ possibly because of methodological differences."

An increased occurence of gluten intolerance in patients with ulcerative colitis, has also been described. ${ }^{14}$ is Higher serum antibody titres to Saccharomyces cerevisiae (baker's yeast) were recently found in patients with Crohn's disease compared with patients with ulcerative colitis or healthy controls. ${ }^{12}$ The response was specific for Saccharomyces cerevisiae strains, and did not include yeast such as Candida albicans. ${ }^{13}$

Antibody levels to a potent immunogenic egg protein, ovalbumin, do not appear to have been studied much in inflammatory bowel disease. ${ }^{216}$

The reason for putatively higher antibody titres to dietary antigens in inflammatory bowel disease might be a defect in the intestinal barrier allowing macromolecules to pass without being degraded. ${ }^{17-19}$ Hollander et $a l^{18}{ }^{19}$ described an increased permeability not only in patients with Crohn's disease but also in their healthy relatives. Thus, the main pathogenetic factor in Crohn's disease might be permeability disorder, possibly genetically determined.

This study concerns the antibody response to various dietary antigens in patients with either Crohn's disease or ulcerative colitis, and their healthy monozygotic twins, aiming at delineating antigen specific reactions and genetic associated predispositions for inflammatory bowel disease.

The study was approved by the Local Ethical Committee, Örebro Medical Center Hospital, Örebro, Sweden.

\section{Methods}

\section{SUBJECTS}

By' matching the Swedish twin registry at the Department of Environmental Hygiene, Karolinska Institute, Stockholm, with the central diagnosis register of hospital inpatients at the National Board of Health and Welfare, Stockholm, a population of monozygotic or dizygotic twins of the same sex has been identified and described earlier. ${ }^{22}$ Thirty four monozygotic pairs with inflammatory bowel disease were found. Those who were younger than 75 years of age and with both twins in each pair still alive were invited to participate in the present investigation

Two recently diagnosed monozygotic pairs with inflammatory bowel disease were also invited. Fifty two of 66 subjects agreed to participate constituting 14 pairs with Crohn's disease and 12 with ulcerative colitis. Five Crohn's disease twin pairs were concordant for the disease and two ulcerative colitis pairs.

The zygosity classification of the Swedish twin registry was used, which relies on questions about childhood resemblance. It has proved to 
be very accurate, and in monozygotic twins a correct classification is obtained in $99 \%$ in comparison with serological methods. ${ }^{23}$

\section{CONTROLS}

One healthy control for each twin was chosen from members of the staff or blood donors, all without any history of gastrointestinal disease. In total, 52 persons were matched for sex and age within two years.

\section{BLOOD SAMPLING}

Venous blood was obtained and allowed to clot at room temperature and centrifuged before withdrawal of serum. Aliquots of serum were frozen at $-70^{\circ} \mathrm{C}$ until analysed.

\section{DETERMINATION OF ANTIBODIES TO FOOD ANTIGENS}

Protein antigen preparations were obtained from Sigma Chemical Co (St Louis, Mo, USA) namely, ovalbumin (A 5503), betalactoglobulin (L 0130), gliadin (G 3375), and mannan (M 3640). Whole yeast cell antigen was prepared in the following way. The cells of ordinary baker's yeast, Saccharomyces cerevisiae, were boiled for one hour, diluted to $25 \mu \mathrm{g} / \mathrm{ml}$ and usually used directly, or stored at $-20^{\circ} \mathrm{C}$ until use.

To prepare antigen solutions, ovalbumin and betalactoglobulin were diluted in phosphate buffered saline, $\mathrm{pH} 7 \cdot 3$ to $25 \mu \mathrm{g} / \mathrm{ml}$, and yeast cell wall mannan to $100 \mu \mathrm{g} / \mathrm{ml}$, whereas gliadin was dissolved in $70 \%$ ethanol and diluted with phosphate buffered saline to $100 \mu \mathrm{g} / \mathrm{ml}$. Whole yeast extract ${ }^{12}$ was used at $25 \mu \mathrm{g} / \mathrm{ml}$.

As antisera, horseradish-peroxidase conjugated rabbit antihuman immunoglobulins were used (Dakopatts, Stockholm, Sweden) - that is, anti-IgG (type P 214), anti-IgA (P 216), and anti$\operatorname{IgM}$ (P 215). Two hundred microlitres antigen solution was added to each well of the microtitreplate (96 well plate, Haegar Plastics, Oslo, Norway), incubated for two hours at $37^{\circ} \mathrm{C}$, and incubated overnight in a moist chamber. The microtitre plates were then washed three times with $250 \mu \mathrm{l}$ phosphate buffered saline with Tween $20(0.05 \%)$.

Patients' sera were diluted 1:25 in phosphate buffered saline-Tween and heat inactivated in a water bath for 30 minutes at $56^{\circ} \mathrm{C}$. Then, $200 \mu \mathrm{l}$ of each serum sample was added to three separate wells for each antigen and incubated for one hour at $37^{\circ} \mathrm{C}$; thereafter, the wells were washed three times with phosphate buffered saline-Tween and incubated with $200 \mu \mathrm{l}$ horseradish-peroxidase conjugates (diluted 1:200 with phosphate buffered saline-Tween), washed again with phosphate buffered saline-Tween, and followed by substrate solution. The plates were light protected until they were read, and the reaction was stopped after 30 minutes by adding $50 \mu \mathrm{l}$ $12.5 \%$ sulphuric acid. The substrate containing $100 \mathrm{ml}$ phosphate buffered saline, $0.4 \mathrm{ml}$ hydrogen peroxide (2\%), and $10 \mathrm{ml} \mathrm{1,4-}$ phenylenediamine dissolved in methanol $(10 \mathrm{mg} /$ $\mathrm{ml}$ ) was freshly prepared and kept in the dark before use. Absorbance was read with an auto- matic ELISA reader (Immuno-Reader NJ-2000, Nippon Intermed KK, Japan).

To obtain a positive control in each plate, serum from a volunteer with measurable levels of anti ovalbumin, anti betalactoglobulin, and anti gliadin of all immunoglobulin classes was used. For negative controls, sera with negligible specific antibody activity to these antigens was used in addition to phosphate buffered salineTween alone. The reference positive control serum was obtained during the period of investigation, frozen at $-20^{\circ} \mathrm{C}$ in aliquots suitable for one day of experiments. When a deviation $>10 \%$ was noted between a positive or negative control measurement, and accumulated median of corresponding controls the whole determination was repeated. To further reduce the influence of methodological errors, the median value of the three samples was used for calculations, and all analyses were performed by the same technician with the same equipment throughout the study. The results were expressed in arbitrary absorbance units per millimetre (absorbance units $/ \mathrm{ml}$ ) without subtraction of background, which was $\leq 0.07,0.06$, and 0.06 absorbance units $/ \mathrm{ml}$ for IgG, IgA, and $\operatorname{IgM}$, respectively. The overall reproducibility over the whole measurement range was within $2 \%$ for triple samples.

\section{STATISTICAL ANALYSIS}

When comparing Crohn's disease and ulcerative colitis disease twins, healthy twins, and controls, Mann-Whitney U test and Student's $t$ test were used. Wilcoxon's sign rank test was used when comparing pairs, where only one individual had developed the disease.

\section{Results}

\section{PATIENT CHARACTERISTICS}

Patients with Crohn's disease had a mean age at diagnosis of 28.5 years (range 20-45), and the actual mean age was $42 \cdot 9$ years (range $34-63$ ). In patients with ulcerative colitis the mean age at diagnosis was $27 \cdot 7$ years (range 17-45), and the actual mean age was 49.1 years (range 24-74). Two patients with Crohn's disease (Crohn's disease twin) had mild diarrhoea and slightly increased serum C-reactive protein and orosomucoid levels, which was treated with sulphasalazine. The other patients were inactive and the only therapy was vitamins or loperamide (Imodium, Janssen Pharmaceutica, Beerse, Belgium). Two patients were on a lactose reduced diet, but only one had verified lactose intolerance. Eight patients were on a fat reduced diet. One of the two patients with increased disease activity was on tube feeding with elemental diet (Reabilan, Roussel Nordiska AB, Stockholm, Sweden) plus milk. All patients with ulcerative colitis (ulcerative colitis twin) were in clinical remission and had normal levels of haemoglobin, C-reactive protein and serum orosomucoid. Six were treated with sulphasalazine. One healthy twin was treated with prednisolone ( $5 \mathrm{mg}$ on alternate days) for chronic hepatitis. None of the ulcerative colitis twins nor their healthy twins were on a special diet. A 
thorough interview did not reveal symptoms suggesting inflammatory bowel disease in the healthy twins. They had remained healthy for an average 14.9 years (range $7-31$ ) and 21.4 years (range 8-40) after diagnosis in the Crohn's disease and ulcerative colitis groups, respectively.

Sigmoidoscopy was performed in the subjects, except in five patients with ulcerative colitis and three patients with Crohn's disease who had had a proctocolectomy and in one Crohn's disease twin pair where both had severe perianal disease preventing sigmoidoscopy. Patients as well as healthy twins showed an inactive rectal mucosa on macroscopic and microscopic assessment.

\section{ANTIBODY LEVEL}

\section{General}

There was a considerable individual variation in antibody response, especially for IgG to all tested antigens but also the level of $\operatorname{IgA}$ and $\operatorname{IgM}$ to yeast cell wall mannan and whole yeast (Saccharomyces cerevisiae) varied much. For this reason a non-parametric method, MannWhitney U test, as well as a parametric method (Student's $t$ test) were used to analyse the results. A few general observations can be made based on the material presented in the Figure and the Table. In ulcerative colitis twins the antibody response (IgA, $\operatorname{IgG}, \operatorname{IgM})$ to tested antigens were similar to that of the healthy twin of patient with ulcerative colitis twins and controls with a few exceptions. In contrast, Crohn's disease twins had higher titres of IgA, IgG, and IgM to yeast cell wall mannan and IgA to whole yeast (Saccharomyces cerevisiae), but not to the other dietary antigens.

Disease location did not have any influence on antibody response with one exception. Crohn's disease patients with small bowel disease only displayed higher IgG to whole yeast (Saccharomyces cerevisiae) than those with combined small and large bowel disease $(t=2 \cdot 469$, $\mathrm{p}=0.024$ ).
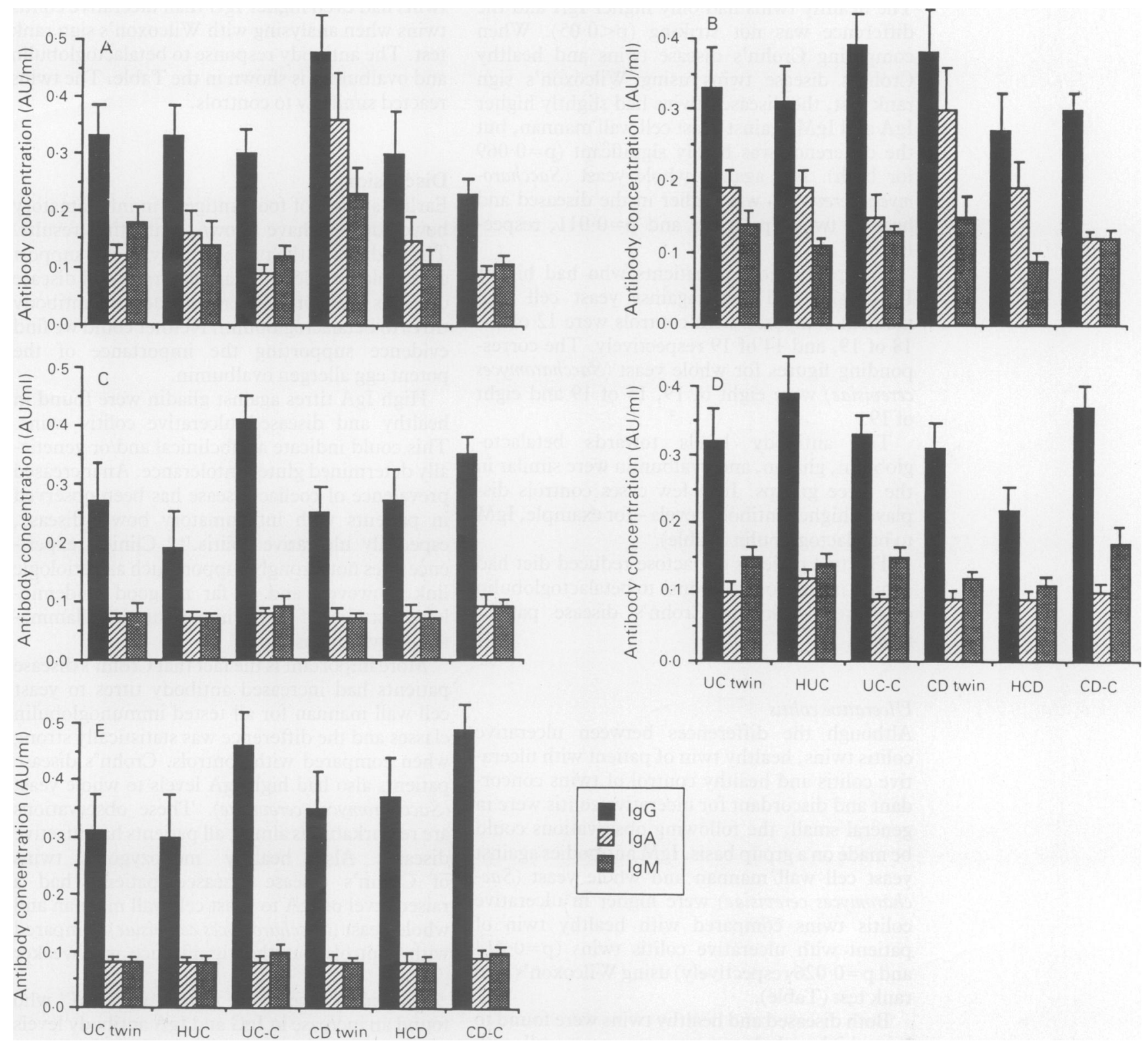

Figure 1: Mean (SEM) serum IgG, IgA and IgM antibody-response ( $A U / m l)$ against $(A)$ yeast cell wall mannan $(M N),(B)$ whole yeast (Saccharomyces cerevisiae) preparation $(Y T),(C)$ betalactoglobulin $(B L G),(D)$ gliadin $(G L)$, and $(E)$ ovalbumin $(O A)$ in patients with ulcerative colitis $(U C$ twin), their healthy monozygotic twins (HUC), matched controls (UC-C;, and in patients with Crohn's disease (CD twin), their healthy monozygotic twins (HCD) and matched controls $(C D-C)$ 
TABLE Summary of statistical evaluations of serum levels in healthy twins, twins with inflammatory bowel disease and healthy control. Only statistically significant differences are depicted

\begin{tabular}{|c|c|c|c|c|c|c|c|c|c|c|c|c|c|c|c|}
\hline \multirow{2}{*}{$\begin{array}{l}\text { Antigen } \\
\text { Antibody }\end{array}$} & \multicolumn{3}{|c|}{ Mannan } & \multicolumn{3}{|c|}{ Yeast } & \multicolumn{3}{|c|}{ Betalactoglobulin } & \multicolumn{3}{|c|}{ Gliadin } & \multicolumn{3}{|c|}{ Ovalbumin } \\
\hline & $\operatorname{Ig} G$ & $\operatorname{Ig} A$ & IgM & $\operatorname{Ig} G$ & $\operatorname{Ig} A$ & $I g M$ & $\operatorname{Ig} G$ & $\operatorname{Ig} A$ & $I g M$ & $\operatorname{Ig} G$ & $\operatorname{Ig} A$ & $I g M$ & $\operatorname{Ig} G$ & $\operatorname{Ig} A$ & $I g M$ \\
\hline $\begin{array}{l}\text { Comparison } \\
1 . \\
\text { CD } \\
\text { CD } \\
\text { HCD } \\
\text { HCD CD-C }\end{array}$ & $>>$ & $\begin{array}{l}>>> \\
>\end{array}$ & $>>$ & & $\begin{array}{l}>>> \\
>\end{array}$ & & & & $\begin{array}{l}<<< \\
<<\end{array}$ & $<$ & & $<$ & & & $<$ \\
\hline $\begin{array}{l}\text { UC HUC } \\
\text { UC UC-C } \\
\text { HUC UC-C }\end{array}$ & & $>$ & $>$ * & & & $>^{\star}$ & $<$ & & & $<^{\star}$ & $\stackrel{>>}{>>}$ & & & & $<$ \\
\hline
\end{tabular}

CD: Twin with Crohn's disease, HCD: Healthy twin of patient with Crohn's disease, CD-C: Healthy control of Crohn's disease and HCD, UC: Twin with ulcerative colitis, HUC: Healthy twin of patient with ulcerative colitis, UC-C: Healthy control of UC and HUC $>=$ values in column 1 larger than in col 2 .

$>=$ values in column 1 larger than in col 2 .
$<=$ values in column 2 smaller than in column 1.

Significances: $<$ and $>(p<0.05),<<$ and $>>(p<0.01),<<<$ and $>>>(p<0.001)$.

$\star$ Indicates that Wilcoxon's sign rank test was used instead of Students $t$ test.

\section{SPECIFIC}

\section{Crohn's disease}

As seen in the Table, Crohn's disease patients had significantly higher levels of all immunoglobulin classes towards yeast cell wall mannan. The healthy twins had only higher IgA and the difference was not striking $(\mathrm{p}<0.05)$. When comparing Crohn's disease twins and healthy Crohn's disease twins using Wilcoxon's sign rank test, the diseased twins had slightly higher IgA and IgM against yeast cell wall mannan, but the difference was barely significant $(p=0.069$ for both). IgA against whole yeast (Saccharomyces cerevisiae) was higher in the diseased and healthy twins $(\mathrm{p}<0.001$ and $\mathrm{p}=0.011$, respectively).

The proportion of patients who had higher $\operatorname{IgG}$, IgA, and $\operatorname{IgM}$ against yeast cell wall mannan compared with controls were 12 of 19 , 18 of 19 , and 14 of 19 respectively. The corresponding figures for whole yeast (Saccharomyces cerevisiae) were eight of 19,15 of 19 and eight of 19.

The antibody levels towards betalactoglobulin, gliadin, and ovalbumin were similar in the three groups. In a few cases controls displayed higher antibody levels - for example, IgM to betalactoglobulin (Table).

The two patients on lactose reduced diet had similar in antibody response to betalactoglobulin compared with the Crohn's disease patient group.

\section{Ulcerative colitis}

Although the differences between ulcerative colitis twins, healthy twin of patient with ulcerative colitis and healthy control of twins concordant and discordant for ulcerative colitis were in general small, the following observations could be made on a group basis. IgM antibodies against yeast cell wall mannan and whole yeast ( $\mathrm{Sac}$ charomyces cerevisiae) were higher in ulcerative colitis twins compared with healthy twin of patient with ulcerative colitis twins $(p=0.014$ and $p=0.026$ respectively) using Wilcoxon's sign rank test (Table).

Both diseased and healthy twins were found to have higher IgA response to yeast cell wall mannan compared with healthy control of twins concordant and discordant for ulcerative colitis $(p=0.046$ and $p=0.031$ respectively, Table $)$.
The most striking finding was for IgA to gliadin, where both healthy twin of patient with ulcerative colitis and ulcerative colitis twins had higher levels than healthy control of twins concordant and discordant for ulcerative colitis $(\mathrm{p}=$ 0.001 and $p=0.012$ respectively). The healthy twins had even higher IgG than ulcerative colitis twins when analysing with Wilcoxon's sign rank test. The antibody response to betalactoglobulin and ovalbumin is shown in the Table. The twins reacted similarly to controls.

\section{Discussion}

Earlier studies of food antigens in inflammatory bowel disease have shown conflicting results. The findings in the present study do not support an aetiologic role in inflammatory bowel disease of cow's milk proteins as reflected by antibody titres to betalactoglobulin. Neither could we find evidence supporting the importance of the potent egg allergen ovalbumin.

High IgA titres against gliadin were found in healthy and diseased ulcerative colitis twins. This could indicate a subclinical and/or genetically determined gluten intolerance. An increased prevalence of coeliac disease has been observed in patients with inflammatory bowel disease, especially ulcerative colitis. ${ }^{1+15}$ Clinical experience does not strongly support such an aetiologic link, however, and so far no good epidemiological studies of gluten intolerance in inflammatory bowel disease exist.

More important is the fact that Crohn's disease patients had increased antibody titres to yeast cell wall mannan for all tested immunoglobulin classes and the difference was statistically strong when compared with controls. Crohn's disease patients also had high IgA levels to whole yeast (Saccharomyces cerevisiae). These observations are remarkable as almost all patients had inactive disease. Also healthy monozygotic twins of Crohn's disease diseased patients had a raised level of $\operatorname{IgA}$ to yeast cell wall mannan and whole yeast (Saccharomyces cerevisiae) compared with controls but the significance was weaker (Table).

This is in accordance with Main et al ${ }^{12}$ who found an increase in IgG and IgA antibody levels to a crude yeast preparation in Crohn's disease patients compared with ulcerative colitis patients, and healthy controls, which was regarded as a reaction to Saccharomyces 
cerevisiae. In a later study the same group ${ }^{13}$ described a significant increase in IgG against 11 of 12 specified strains of Saccharomyces cerevisiae. A reaction to Candida albicans was not seen. We have used a similar method to prepare a crude yeast antigen mixture but also analysed the specific response to mannan which is a cell wall component in yeasts. In our study, all but two Crohn's disease patients had inactive disease, but they had increased antibody levels to yeast cell wall mannan and whole yeast (Saccharomyces cerevisiae). Nothing was mentioned about disease activity in the studies by Main et $a l^{12}$ and McKenzie et al. ${ }^{13}$ Notable in the present study was the increase in IgA antibodies to yeast cell wall mannan and whole yeast (Saccharomyces cerevisiae) also in healthy twins, which might indicate a genetic predisposition.

In the present study more than 240 statistical calculations were made, which must be considered when evaluating the results. To avoid differences by chance a significance level of at least $p<0.01$ should be required. The response towards yeast cell wall mannan in Crohn's disease twins was very distinct and significant increased levels of all immunoglobulins tested were found.

Whether yeast mannan is an aetiological agent in Crohn's disease remains to be proved. Alternatively, yeast cell wall mannan may mimic a high mannose containing molecule, which is the offending compound and towards which the primary antibody response is directed. Taking this speculation even further, one might look for aberrant glycosylation patterns in Crohn's disease resulting in autoantibodies to high mannose containing glycoconjugates. Because the immune reaction is specific for yeast cell antigen(s) and apparently distinct for Crohn's disease, the primary disorder is probably not increased permeation of any dietary antigen. The permeability disorder seen in Crohn's disease ${ }^{17-19}$ is more likely an effect of the inflammatory process.

We are grateful to $\mathrm{Mr}$ Bertil Larsson for skilled technical assistance. This study was supported by Örebro County Research Committee, AB Pharmacia (Uppsala, Sweden) and the Professor Nanna Svartz Foundation (awarded to EL) and by the Swedish
Medical Research Council (Project, No 6251), the Swedish Society against Rheumatism and King Gustaf Vth 80-year Foundation (awarded to K-EM)

1 Andresen AFR. Gastrointestinal manifestations of food allergy Med F Rec 1925; 122: 271-5.

2 Taylor KB, Truelove SC. Circulating antibodies to milk proteins in ulcerative colitis. BMF 1961; ii: 924-9.

3 Taylor KB, Truelove SC, Wright $\mathbf{R}$. Serologic reactions to gluten and cow's milk proteins in gastrointestinal disease. Gastroenterology 1964; 46: 99-108.

4 Sewell P, Cooke WT, Cox EV, Meynell MJ. Milk intolerance in gastrointestinal disorders. Lancet 1963; ii: 1132-5.

5 Dudek B, Spiro HM, Thayer WR. A study of ulcerative colitis and circulating antibodies to milk proteins. Gastroenterology $1965 ; 49: 544-7$.

enterology $1965 ; 49: 544-7$.
6 Jewell DP, Truelove SC. Circulating antibodies to cow's milk proteins in ulcerative colitis. Gut 1972; 13: 796-801.

7 Falchuk KR, Isselbacher KJ. Circulating antibodies to bovine albumin in ulcerative colitis and Crohn's disease. Characterization of antibody response. Gastroenterology 1976; 70: 5-8.

8 Lerner A, Rossi TM, Park B, et al. Serum antibodies to cow's milk proteins in pediatric inflammatory bowel disease. Acto Paediatr Scand 1989; 78: 384-9.

9 Paganelli R, Pallone F, Montano S, et al. Isotypic analysis of antibody response to food antigen in inflammatory bowe disease. Int Archs Allergy Appl Immunol 1985; 78: 81-5.

10 Knoflach P, Park BH, Cunningham R, et al. Serum antibodies to cow's milk proteins in ulcerative colitis and Crohn's disease. Gastroenterology 1987; 92: 479-85.

11 McCaffery TD, Kraft SC, Rothberg RM. The influence of different techniques in characterizing human antibodies to different techniques in characterizing human antibodies

12 Main J, McKenzie H, Yeaman GR, Kerr MA, Robson D Pennington CR, et al. Antibody to Saccharomyces cerevisiae (baker's yeast) in Crohn's disease. BMF 1988; 297: 1105-6.

13 McKenzie H, Main J, Pennington CR, Parratt D. Antibody to selected strains of Saccharomyces cerevisiae (baker's and brewer's yeast) and Candida albicans in Crohn's disease. Gu 1990; 31: 536-8.

14 Gillberg R, Dotevall G, Åhrén C. Chronic inflammatory bowel disease in patients with coeliac disease. Scand $\mathcal{F}$ Gastroenterol 1982; 17: 491-6.

15 Kitis G, Holmes GKT, Cooper BT, Thompson H, Allan RN. Association of coeliac disease and inflammatory bowel disease. Gut 1980; 21: 636-41

16 Gray JG. Antibodies to cow's milk in ulcerative colitis. $B M F$ 1961; ii: 1265-6.

17 Olaison G, Leanderson P, Sjödahl R, Tagesson C. Intestinal permeability to polyethyleneglycol 600 in Crohn's disease. Peroperative determination in a defined segment of the small intestine. Gut 1988; 29: 196-9.

$18 \mathrm{Katz} \mathrm{KD}$, Hollander D, Vadheim CM, et al. Intestinal permeability in patients with Crohn's disease and their healthy relatives. Gastroenterology 1989; 97: 927-31.

19 Hollander D. Crohn's disease - a permeability disorder of tight junction? Gut 1988; 29: 1621-4.

20 Stenhammar L, Brandt $\AA$, Wågemark J. A family study of coeliac disease. Acta Paediatr Scand 1982; 71 : 625-8.

21 Kjellman N-IM, Björkstén B, Hattevik G, Fälth-Magnusson $\mathrm{K}$. Natural history of food allergy. Ann Allergy 1988; 61: K. N.7.

22 Tysk C, Lindberg E, Järnerot G, Floderus-Myrhed B. Ulcerative colitis and Crohn's disease in an unselected population tive colitis and Crohn's disease in an unselected population
of monozygotic and dizygotic twins. A study of heritability and influence of smoking. Gut 1988; 29: 990-6.

23 Cederlöf R, Friberg L, Jonsson E, Kaij L. Studies on similarity diagnosis in twins with the aid of mailed questionnaires. Acta Genet 1961; 11: 338-62. 